\title{
History and prospects of Geriatrics
}

\section{Alexandre Leopold Busse ${ }^{1}$, Wilson Jacob Filho ${ }^{2}$}

A ging is part of the evolution of living beings since their origin, but the attention to its determining factors and effects is far more recent, assuming that there has been a long period in which the stage in life that comes after functional fullness was less important and, consequently,worthless when it comes to understanding and attention.

In ancient times, the Egyptian hieroglyphics (2800 BC) represented the elderly as a person with an arched back. It is perhaps one of the first descriptions of the consequences of osteoporosis. On the other hand, Hippocrates (450 BC) analyzed aging with great propriety, in one of the first allusions to the possibility of interfering with its consequences of aging: "The functional body parts, if used sparingly and exercised on the functions to which they are adapted, develop and age slowly. When they are useless, they are more prone to disease, grow with defects and age quickly"1.

Roger Bacon (1214-1294), a Franciscan friar, wrote a book on aging in which he suggested that aging can be mitigated by means of a controlled diet, proper rest, exercise, a moderate lifestyle, good hygiene and by inhaling the breath of a young virgin. Near the end of the nineteenth century, the concept of hormonal aging began to develop:
Victor Horsley observed that thyroid deficiency could result in "mere senility" and Brown-Séquard, at the age of 70 , discovered that he was getting tired in the evening and introduced the first testicular extract injections ${ }^{1}$.

The word "geriatrics", derived from gerousia (a group of men older than 60 who headed the Legislative Council of Athens), was introduced by Ignatz Leo Nascher. He, who was born in Austria, obtained his medical degree at the University of New York in 1885 and wrote a series of articles and a book on geriatrics ${ }^{1}$.

The British had great influence in the creation of the basic principles of geriatrics, which would later be validated by research developed mainly in the United States. The development of modern geriatrics is credited to Marjory Warren (1897-1960). She worked at the Middlesex Hospital in London, where she broke ground with motivational rehabilitation programs for the elderly. Eric Brooke, at the St. Hellier Hospital in Charston, introduced the concept of home visits for the rehabilitation of elderly people. The first geriatrics course in the world was at the Glasgow University, and it is attributed to Dr. Ferguson Anderson in 1965. Brocklehurst codified the basic principles of geriatrics in his famous books and Bernard Isaacs (19241995) created the term "geriatrics giants" to describe the

\footnotetext{
1.Assistant Professor of the Geriatrics Discipline of the University of São Paulo's Faculty of Medicine (FMUSP); Assistant Physician in the Geriatrics Service of the Clinical Hospital of the University of São Paulo's Faculty of Medicine (Hospital das Clínicas da Faculdade de Medicina da Universidade de São Paulo - HCFMUSP). E-mail: alexandre.busse@hc.fm.usp.br.

2.Full Professor of the FMUSP's Geriatrics Discipline; Director of the Geriatrics Service of the HC-FMUSP. Email: wiljac@usp.br. Mailing address: Hospital das Clínicas da Faculdade de Medicina da USP, Clínica Médica, Geriatria. (Clinical Hospital of USP's Faculty of Medicine, Medical Clinic, Geriatrics) Rua Dr. Enéas de Carvalho aguiar, 155 - $8^{\circ}$ andar - Bloco 8L - Setor Laranja. Cerqueira Cesar. CEP: 05403900 - Sao Paulo, SP, Brasil.
} 
main geriatric syndromes ${ }^{1}$.

In Brazil one of the first events themed on aging was organized in the Santa Casa de Misericórdia (Holy House of Mercy) of Rio de Janeiro in 1957 which triggered the founding of the Brazilian Society of Geriatrics (Sociedade Brasileira de Geriatria - SBG) in 1961, initially chaired by Prof. Dr. Deolindo Couto. In 1969, the 1st National Congress of Geriatrics and Gerontology was held. Thus, the word Gerontology was included and the abbreviation became SBGG. And the Society began to accept as partners, other professional categories involved in aging ${ }^{2}$.

In 1976 the São Paulo Section of the SBGG was founded, and had Dr. Moisés Barmak as its first President, Prof. Vanderlei Nogueira da Silva, from the Faculty of Medicine of the University of São Paulo (FMUSP) as its Vice President and Dr. Nei Perracini as its Scientific Director. Next, the elderly health care centers began to develop in the various teaching hospitals. The Service of Geriatrics of FMUSP's Clinical Hospital (HCFMUSP) was created in 1982 and the FMUSP's Geriatrics Discipline was made official in 1992. Since then, fortunately, the increase in number and quality of the Services and Residency Programs has been exponential, which is being followed by an increasing number of graduates in Geriatrics and Gerontology by the $\mathrm{SBGG}^{2}$.

We live in an unprecedented time in human history. At no other time in our evolution did we have such an evident change in life expectancy and the same time a decrease in fertility rates. What happened in the last half of the twentieth century and is happening in the first half of the twenty-first century will most likely be remembered as the greatest epidemiological transition of all time. The demographic projections suggest that the populations of all countries are aging, which will have large effects on the social, economic and health systems. The world population aged 60 or over tends to increase from 841 million in 2013 to over 2 billion in 2050, when it should surpass the number of children ${ }^{3}$.

This change in demographics offers both opportunities and challenges. Most people aspire to live a long and healthy life, and the elderly can provide valuable economic, social, cultural and family resources. In addition to their potential ability to work, the elderly embody a large pool of human capital, especially when it comes to education and work experience. A lifetime of experience can make them more adherent to assessing and addressing a wide range of situations, not to mention guidance to young people. However, the ageing of the population can also be associated with a decrease in the active population and an increased demand for health care, social assistance and social pensions ${ }^{4}$.

Currently the main causes of death and disability at an older age are non-communicable diseases. Many of them can be prevented or delayed. The early strategies of life have even been increasingly emphasized when compared with healthy behaviors and control of risk factors. Some studies suggest that about $25 \%$ of the heterogeneity related to health and functional ability in old age is genetically determined, and the rest is strongly related to behaviors and inequalities throughout the person's whole life ${ }^{4}$.

Other comprehensive social changes are transforming society and interacting with aging, affecting the social and intergenerational dynamics. Many elderly people will start living alone or only with their spouses. The increase in the participation of women in the workforce certainly brings benefits to the social and economic development, but it also reduces the availability of this traditional family role in providing care while the demand is increasing. Therefore one can predict that in many countries the number of dependent elderly people will increase, without relatives who can take care of them and also without trained caregivers or institutions able to welcome them. However there are no historical examples available to guide decision-making regarding these social changes, so the countries will have to rely on new analysis to propose new public policies ${ }^{5}$.

As the elderly population increases we will have an epidemic of chronic diseases. The greatest increases have been occurring with the following diseases: dementias, cerebrovascular accident, chronic obstructive pulmonary disease, diabetes, heart failure and coronary insufficiency. Actually, the elderly are more likely to have several coexisting and interrelated problems, which is called multimorbidity. One of the consequences of multimorbidity is the use of many drugs. The use of 4 different drugs or more is called polypharmacy. This is associated with a greater risk of adverse interactions and reactions, which can often decompensate the chronic 
diseases. It is not uncommon that a simple adjustment of prescription makes various symptoms of elderly people who seek the physician better ${ }^{6}$.

We will discuss some widely used definitions in geriatrics so we can hereinafter focus on 21 st-Century Geriatrics $^{7}$

Geriatrics is the field of medicine that deals with the aging process; the prevention, diagnosis and treatment of health problems in the elderly; the socio-economic conditions that affect elderly healthcare.

Gerontology, in turn, it is a broader term which means the study of the elderly and of the factors related to aging, both in humans and in other living beings. Therefore, it includes Geriatrics and interfaces with the various sciences that study the wide range of determinants of this evolution. Thus we can speak of Social Gerontology, Cellular Gerontology and Gerontological Epidemiology.

Functional ability and functional reserve: The maximum performance ability in the face of an extreme situation can be defined as the functional ability of a body. Therefore, we can think of maximum renal functional ability as the maximum volume of blood per unit of time it is able to purify, that is, for its clearance. A human being, in his/her prime, has the functional ability of his/her organs well above what he/she needs in order to live, that is, his/ her basal needs. A young person can live well with one kidney, due to his/her functional reserve, that is, part of his/her functional ability covers the basal needs and much of it - the functional reserve - is intended for situations of major temporary demands, however planned (as it is for the use of all cardiopulmonary functional reserve during a marathon), for the maintenance of homeostasis in situations of involuntary overload (a systemic disease, bleeding or sudden exposure to cold, for example) or even in the case of permanent aggression (as in chronic liver disease in its early stages) when the function of the organ remains unaffected until the later stages of the disease.

Aging is a universal and inevitable process of continuous evolution, characterized by the progressive loss of the functional reserve of each organ responsible for our homeostasis. We call this narrowing of the functional reserve homeostenosis. It is worth stressing that, in practice. What we find in the living being that ages in the wild, outside laboratory conditions, is the sum of the two processes that are identified as follows: a) senescence is natural process of aging and to the set of inexorable and predictable changes determined by this process. Senescence involves loss of functional reserve without incurring in failure per se, even at very advanced ages. b) senility is the term we use to describe the changes or processes unrelated to physiological aging and determined by diseases and bad life habits, such as physical inactivity and smoking. These aggravations, associated with the decrease in functional reserve expected in the elderly, may lead to situations of organ or function failure, as well as the inability to perform daily life activities, dependence and loss of autonomy.

Autonomy, according to the WHO, is the ability to control, understand and take personal decisions about how to live according to rules and to an individual's own preferences on a daily basis.

Independence is the ability to perform functions related to daily life, that is, the ability to live in its context without any help or with little help from others.. As one can easily infer, the context and the environment in which a person lives can be favorable or unfavorable to a person's independence.

\section{Geriatrics in the 21 st century}

To promote the health of his/her patients, the physician should be able to discuss his/her points of view with patients, which will have more and more access to information. In this context, the updating of knowledge and the ability to transmit it become increasingly important, which reiterates the importance of continued and careful learning and the acquisition of communication skills, both essential to the effective practice of modern medicine. The professional who intends to serve the elderly must develop his/her communication skills, not only in the intergenerational aspect, on which he/she may rely for the contact with his/her patients, but also in the interprofessional aspect, by frequently being part of an interdisciplinary team, whose effectiveness stems also from the ability of interaction among its members. Therefore, it would be quite appropriate for the initial and conceptual approach of Geriatrics and Gerontology to occur comprehensively during graduation ${ }^{7}$.

One of the most distinctive aspects of Geriatrics 
is a multidimensional approach to the aging individual. The Global Assessment for the Elderly (Avaliação Global do Idoso - AGI) is a multifaceted approach that focuses on understanding the physical, cognitive, psychological and social matters of an elderly person. Also known as Comprehensive Geriatric Assessment or Global Geriatric Assessment, it is the starting point for a comprehensive approach to the health of the elderly, its crucial component is the comprehensive assessment of the functional ability and of the geriatric syndromes. From the AGI, it is possible to obtain diagnosis of diseases, to map the health risks and to plan the practices. Apart from the usual clinical assessment, there are fundamental points that should be highlighted such as: humor, cognition, medication use, risk of falling, physical activity, vaccinations, lifestyle habits, sphincter incontinence, sexuality, sensory loss and oral health ${ }^{8}$.

A review of its benefits concluded that the AGI is more efficient than the usual assessment because it provides an overview of the elderly, improves diagnostic accuracy, generates subsidies for treatment and long-term monitoring, increases survival, reduces the number of emergency assistance events, decreases the number of admissions to psychiatric institutions and reduces healthcare costs. The action of a multidisciplinary team is paramount so that interventions originating from the assessment can be carried out. Only then can the AGI be considered effective ${ }^{9}$.

The functionality can be assessed by questioning the ability to independently perform basic activities of daily life (atividades básicas de vida diária - AVDs) and instrumental

\section{REFERENCES}

1. Morley JE. A brief history of geriatrics. J Gerontol A Biol Sci Med Sci. 2004;59(11):1132-52. doi: 10.1093/ gerona/59.11.1132.

2. História da Sociedade Brasileira de Geriatria e Gerontologia. Available at: http://sbgg.org.br/sbgg/historico/

3. Chatterji S, Byles J, Cutler D, Seeman T, Verdes E. Health, functioning, and disability in older adults: present status and future implications. Lancet. 2015;385:563-75. doi: 10.1016/ S0140-6736(14)61462-8.

4. Beard JR, Bloom DE. Towards a comprehensive public health response to population ageing. Lancet. 2015;385:658-61. doi: 10.1016/S0140-6736(14)61461-6.

5. Bloom DE, Chatterji S, Kowal P, Lloyd-Sherlock P, McKee activities of daily life (atividades instrumentais de vida diária - AIVD). The basic activities are: moving around, dressing, bathing, feeding and using the bathroom. The instrumental activities are: using means of transportation, using the phone, shopping, preparing meals, washing clothes, handling money and taking medicine ${ }^{10,11}$.

It is also possible to have an assessment of the functional condition with objective measurements obtained through physical fitness indicators such as: flexibility, muscular strength, agility and balance ${ }^{12}$. The ability to perform daily activities in a normal pattern, according to socially constructed behaviors, involves the physical, mental and psychosocial functions. The assessment of functionality allows for: the detection of risk situations, the identification of areas of dysfunction, the monitoring of functional decline, the establishment of a care plan which is adequate to the care demands, the identification of the need for using specialized services and establishing links to the multidimensional understanding of the cases ${ }^{13}$.

The teaching of Geriatrics and Gerontology should increasingly pervade the undergraduate curriculum of undergraduate courses, but it is essential that in the future we can count on trained professionals in primary care and enough specialists to care for the more vulnerable elderly. The research in Geriatrics and Gerontology has huge potential for growth. Whether it is because, for a long time, the elderly were excluded from clinical trials for most diseases, and the results were extrapolated for this age group. Or because most countries need solutions to the socio-economic impact of population ageing ${ }^{14}$.

M, Rechel B, Rosenberg L, Smith JP. Macroeconomic implications of population ageing and selected policy responses. Lancet. 2015;385:649-57. doi: 10.1016/S01406736(14)61464-1.

6. Mathers CD, Stevens GA, Boerma T, White RA, Tobias MI. Causes of international increases in older age life expectancy. Lancet. 2015;385:540-8. doi:10.1016/S01406736(14)60569-9.

7. Jacob-Filho W. O envelhecimento em diferentes contextos: populacional, individual e social. In: Martins MA, Carrilho FJ, Alves VAF. Clínica médica. São Paulo: Manole; 2009. p.782-90.

8. Busse AL, Jacob-Filho W. Envelhecimento: uma visão 
multidisciplinar. In: Jacob-Filho W, Jorge AAL, Busse AL. Envelhecimento: uma visão interdisciplinar. São Paulo: Atheneu; 2015. p.3-10.

9. Gold S, Bergman H. Comprehensive geriatric assessment revisited again. Age Ageing. 2000;29(5):387-8. doi: 10.1093/ ageing/29.5.387.

10. Lawton MP. The functional assessment of elderly people. J Am Geriat Soc. 1971;19:465-81. doi: 10.1111/j.15325415.1971.tb01206.x.

11. Ramos LR, Simões E, Albert SM. Dependency on daily living and cognitive impairment strongly predicted mortality among urban elderly residents in Brazil: a two-year follow-up. J Am Geriatr Soc. 2001;49:1168-75. doi: 10.1046/j.15325415.2001.49233.x.

12. Guralnik JM, Simonsick EM, Ferrucci L, Glynn RJ, Berkman
LF, Blazer PA, et al. A short physical performance battery assessing lower extremity function: association with selfreported disability and prediction of mortality and nursing home admission. J Gerontol. 1994;29:M85-M94. doi: 10.1093/geronj/49.2.M85.

13. Duarte YAO, Lebrão, ML, Lima FD. Contribuição dos arranjos domiciliares para o suprimento de demandas assistenciais dos idosos com comprometimento funcional em São Paulo, Brasil. Rev Panam Salud Publica. 2005;17(5/6):370-8. http://dx.doi. org/10.1590/S1020-49892005000500009.

14. Cox L, Kloseck M, Crilly R, McWilliam C, Diachun L. Underrepresentation of individuals 80 years of age and older in chronic disease clinical practice guidelines. Can Fam Physician. 2011;57:e263-9. Available at: http://www.ncbi. nlm.nih.gov/pmc/articles/PMC3135465/. 